\title{
Well-being and health in adolescents with disabilities
}

\author{
Lúcia Canha ${ }^{1 *}$, Celeste Simões ${ }^{1}$, Margarida Gaspar Matos ${ }^{1}$ and Laura Owens ${ }^{2}$
}

\begin{abstract}
Several studies have indicated that adolescents with disabilities are more dissatisfied with their quality-of-life and have more complaints regarding their health in comparison to their nondisabled peers.

Objective: In this study the authors investigated the self-ratings of health and its relationship to life satisfaction in students with disabilities. In addition, similarities and differences between students with and without disabilities regarding their self-ratings of health, life satisfaction, and psychological and physical symptoms were analyzed.

Method: The sample included 213 students with disabilities ( $M=14.12$ years old; $S D=1.97 ; N=213$ ) and a control group of 242 students without disabilities ( $M=14.15$ years old; $S D=1.97 ; N=242$ ). Participants completed a questionnaire from the HBSC study which was administered in the classroom.

Results: The results showed that sudents with disabilities who report a better health self-rating were happier and more satisfied with their lives. Comparison between groups showed that students with disabilities presented more symptoms and lower health perception than their nondisabled peers.

Conclusions: The findings from this study reinforce the need for interventions empowering adolescents with disabilities to better manage their health. More research is needed to replicate these results between different types of disabilities.

Keywords: Disability, Health Promotion, Well-being
\end{abstract}

\section{Background}

The concept of quality of life (QOL) has increasingly become a focus for research and application in the fields of education/special education, health care (physical and behavioral), social services (disabilities and aging), and families (Schalock, 2004). The World Health Organization (WHO) defines quality of life (QoL) as "an individual's perception of their position in life in the context of the culture and value systems in which they live and in relation to their goals, expectations, standards, and concerns" (WHOQOL Group, 1994). QoL is a broad-ranging concept affected in a complex way by the person's physical health, psychological state, level of independence, social relationships, and their relationship to salient features in their environment (WHO, 1997). The objective component of quality of life consists of objective features, which

\footnotetext{
* Correspondence: lucia.canha@gmail.com

${ }^{1}$ Department of Education, Social Sciences and Humanities, Faculty of Human Kinetics/University of Lisbon, (Estrada da Costa), Lisboa, (1495-688), Portugal

Full list of author information is available at the end of the article
}

can be observed and measured in the public domain; the subjective component, also called subjective well-being, holds the personal experiences (Diener, 2009). Specifically, subjective well-being refers to people's evaluations of their lives, which can be judgments such as life satisfaction, evaluations based on feelings, including moods and emotions (Diener and Chan 2011).

Several studies have indicated that adolescents with disabilities are more dissatisfied with their quality of life (QoL) in comparison with their nondisabled peers. Edwards, et al. (2003) found that a group of adolescents with varying types of disabilities (e.g., physical, emotional, or learning disability) reported lower QoL than adolescents without disabilities. Another study by Sacks and Kern (2008) examined quality of life differences between adolescent students with disabilities and found that these students were significantly more dissatisfied with their overall quality of life, as well as the sub areas assessed which include general quality of life, self, relationships, and environment, than their nondisabled peers. Similarly, Watson and Keith (2002) found that students with 
disabilities receiving special education services in public schools scored lower than nondisabled students on four QoL factors measured: satisfaction, well-being, social belonging, and empowerment/control. Additionally other studies have reported a clear relationship between QoL and other aspects of life for youth with disabilities. Wolf-Branigin et al. (2007) suggest that one of the reasons it is critical to improve quality of life is its impact on the future life of young people with disabilities. In addition, the availability of opportunities for decision and choice making appears to be an essential component of a life of quality (Brown and Brown 2009).

The concepts of QoL, life satisfaction and health appear closely related in the literature. In fact, there is evidence indicating that subjective well-being causally influences health (Diener and Chan 2011). According to the Ottawa Charter for Health Promotion (WHO, Regional Office for Europe 1986), health is a state of complete physical, mental, and social well-being, not merely the absence of disease or infirmity. Health promotion, in turn, is the process of enabling people to increase control over and improve their health. It is presented here as a positive concept which highlights the personal and social resources as well as physical skills. Health is seen as a resource for everyday life not the objective of living. According to O'Donnell (2009), health promotion "is the art and science of helping people discover the synergies between their core passions and optimal health, enhancing their motivation to strive for optimal health, and supporting them in changing their lifestyle to move toward a state of optimal health. Optimal health is a dynamic balance of physical, emotional, social, spiritual, and intellectual health. Lifestyle change can be facilitated through a combination of learning experiences that enhance awareness, increase motivation, and build skills and, most important, through the creation of opportunities that open access to environments that make positive health practices the easiest choice" (page iv). According to O'Donnell, people will be motivated to improve their health, if they recognize that improving their health will help to meet their passions. It is important to notes that, optimum health is a dynamic condition that changes with the circumstances of life.

These views of health can offer a perspective of people with disabilities as people as a whole, rather than a focus on their impairments (Kim and Fox 2006). People with disabilities tend to define health and wellness as being independent and self-determined; having both physical and emotional well-being, and freedom from pain (Krahn et al. 2006). Within these conceptualizations of health, measures of self-perceived health and health-related quality-of-life become essential (Krahn et al. 2006). Evidence suggests that a positive self-appraisal of health may mitigate the averse effect of illness or disability on life satisfaction (Diener, 2009; Patrick et al. 2002). Self-rated health is a subjective indicator of general health; it is found to be predictive of objective health outcomes in adults (Burstroem and Fredlund 2001), and is a more appropriate measure of adolescent health than traditional morbidity and mortality measures (Currie et al. 2008).

In Portugal, the self-rating of health has been related to several of the social and psychological variables in adolescents with disabilities (Simões et al. 2008a, b; Matos, 2003) and without disabilities (Simões et al. 2008a, b). However, there are few studies assessing self-rated health and life satisfaction of youth with disabilities. Previous studies found that adolescents with disabilities often reported that they felt unhappy and had a poorer perception of their health (Canha, 2010; Simões et al. 2010). However more studies are needed to look at the relationship between health and life-satisfaction to compare these factors with youth without disabilities.

The indicators used for this study were from the Health Behavior in School-aged Children (HBSC) study, a cross-national research study conducted in collaboration with the World Health Organization (WHO) (Currie et al. 2011). All HBSC surveys have used key aspects of health and well-being and are based on individuals ages 11,13 and 15 . Specifically, this study analyzes data from four HBSC indicators: self-rated health, health complaints (psychological and physical), life satisfaction and happiness.

The first objective of this study was to analyze selfrated health and its relationship with life satisfaction in students with disabilities. The second objective of this study was to compare three indicators-self-rated health, psychological and physical symptoms, and life satisfaction-between students with and without disabilities. The four research questions for this study were: (1) Verify if there was an association between self-rating of health and perceptions of life satisfaction and happiness ; (2) Investigate to what extent the self-rating health of students with disabilities was different comparatively to students without disabilities; (3) Analyze the extent to which students with disabilities perceive life satisfaction and psychological and physical symptoms differ from students without disabilities; and (4) Verify whether the perceptions of health varies according to age.

\section{Methods}

\section{Participants and recruitment}

Data used in this study were from the Portuguese HBSC 2006 study (Matos \& Equipa do Projecto Aventura Social, 2006). The Portuguese HBSC data were collected through self-completion questionnaires administered in the classroom. From the 1194 public schools, a random sample of 136 schools, stratified by the five regions in Portugal, was selected. Within each school, classes were then randomly selected. In accordance with the international HBSC 
protocol, this study used a cluster sample drawn from 6th, 8th and 10th grades (students aged 11, 13 and 15). In Portugal, it is common for students with disabilities to be retained in a grade level. For example, a 6th grade class may have students with disabilities who are 14 years of age. As a result, the authors included students with disabilities aged $16-20$ in the study.

In total, 296 classes were selected; 96 sixth grade, 102 eighth grade, and 98 tenth grade. The final national sample included 4877 subjects, of which 213 were students with disabilities. The breakdown of disabilities from the 213 included the following: visual impairments (32.9\%); physical disabilities (11.7\%); Deaf (7.0\%); learning disabilities (8.5\%); speech disabilities (4.2\%); and "Other" (e.g., asthma, diabetes and epilepsy) (35.7\%). A random sample of $7 \%$ of the total of students without disabilities, representing the 242 students, was identified for the control group. Participants with disabilities ranged in age from $10-20$ years, with a mean age 14.12 years, $(S D=1.97 ; N=213)$. The participants without disabilities ranged in age from 11 to 20 years, with a mean age 14.15 years, $(S D=1.97 ; N=242)$. The mean ages between the two groups were not significant.

\section{Instrument}

The Health Behavior in School-aged Children (HBSC) is a cross-national research study conducted in collaboration with the WHO Regional Office for Europe. The study aims to gain new insight into, and increase our understanding of, young people's health and well-being, health behaviors and their social context (Currie et al. 2011). By 1983 the HBSC study was adopted by the WHO Regional Office for Europe as a collaborative study. HBSC now includes 43 countries and regions across Europe and North America. The international standard questionnaire produced for every survey cycle enables the collection of common data across all participating countries and thus enables the quantification of patterns of key health behaviors, health indicators and contextual variables. These data allow cross-national comparisons to be made and, with successive surveys, trend data is gathered and may be examined at both the national and cross-national level. The international network is organized around an interlinked series of focus and topic groups related to the following areas: body image, bullying and fighting, eating behaviors, health complaints, injuries, life satisfaction, obesity, oral health, physical activity and sedentary behavior, relationships: family and peers, school environment, self-rated health, sexual behavior, socioeconomic environment, substance use: alcohol, tobacco and cannabis, and weight reduction behavior. This study has the approval of the S. João Hospital scientific committee, an ethical national committee and the national commission for data protection, and strictly follows all the guidelines for human rights protection.

The findings presented here are based on four indicators from HBSC: self-rated health, health complaints (psychological and physical) and, life satisfaction and happiness. All HBSC surveys have used these key aspects of health and well-being. People's subjective health experience is a central indicator, often investigated by asking them to rate their own health.

\section{Self-rated health}

Self-rated health is a subjective indicator of general health. It is found to be predictive of objective health outcomes in adults (Burstroem and Fredlund 2001), and is a more appropriate measure of adolescent health than traditional morbidity and mortality measures (Currie et al. 2008). Young people were asked to describe their health ("would you say your health is ... ?"). Responses are provided on a 4 -point scale: $1=$ Poor, $2=$ Fair, $3=$ Good, 4 = Excellent.

\section{Subjective health complaints}

A standard symptom checklist was used to measure the frequency of occurrence of subjective health complaints. Psychosomatic complaints or symptoms are thought to be indicators of how adolescents are responding to stressful situations. Such subjective health complaints can place an immense burden on the individual and on the health care system (Currie et al. 2008). The HBSC symptom checklist represents a non-clinical measure of mental health, reflecting two facets of health-one psychological and one somatic (Hetland et al. 2002). All the items on the checklist can nevertheless be used together to measure psychosomatic complaints (Hagquist and Andrich 2004). Each symptom was rated by participants on a 5 -point scale ranging from 0 (rarely or never) to 5 (almost every day). The Psychological Symptoms Scale (SS-Psychological) was obtained through the sum of items that assess the frequency of occurrence of the following symptoms: feeling low, irritability or bad temper, feeling nervous, difficulties in getting to sleep and feeling fear. The Physical Symptoms Scale (SS-Physical) was obtained through the sum of items that assess the frequency of occurrence of the following symptoms: headache, stomachache, back-ache, feeling dizzy and neck and shoulders pains.

\section{Life satisfaction}

The indicator of life satisfaction was used to measure young people's global evaluation of their lives. The Life satisfaction scale (LSS) was derived from the measurement technique known as the Cantril ladder (Cantril, 1965). The Cantril ladder has 10 steps: the top of the ladder indicates the best possible life, and the bottom, 
the worst possible life. Young people were asked to indicate the step of the ladder at which they would place their lives at present; the top of the ladder (10-the best possible life)and the bottom ( 0 - the worst possible life). A score of 6 or more is defined as a positive level of life satisfaction.

\section{Happiness}

The happiness perception was measured by the following question: "In general, how do you feel about your life at present?" Response options were: $1=\mathrm{I}$ 'm not happy at all, $2=\mathrm{I}$ don't feel very happy, $3=\mathrm{I}$ feel quite happy, $4=\mathrm{I}$ feel very happy.

\section{Statistical procedures}

To analyze the self-rated health and its relationship with life satisfaction in students with disabilities two statistics tests were utilized. A Chi-square test was conducted to analyze the association between the self-rated health and the perception of happiness. A one-way analysis of variance (ANOVA) was used to compare differences in life satisfaction across three levels of self-related health (excellent heath, good health and poor health).

To compare the four indicators (self-rated health, health complaints, life satisfaction and happiness) between students with and without disabilities, two statistical tests were used. A Chi-square test was conducted to compare how the health perceptions (excellent heath, good health and poor health) differed between groups (with and without disabilities). A Test $t$ was used to compare life satisfaction and psychological and physical symptoms between both groups of students with and without disabilities. Finally, a one-way analysis of variance (ANOVA) was used to compare differences in perceptions of health by age in the two study groups.

\section{Results}

\section{Demographic characteristics}

A comparison of demographic characteristics between students with and without disabilities can be seen on Table 1. Related to nationality, the majority of the subjects were Portuguese, followed by African. Only subjects in the control group had participants from Brazil and Eastern European countries. There were no significant differences found between subjects with and without disabilities within grade level or in nationality. However, there was a significant difference in gender within the disabilities group which had significantly more females (56 \%) than in the nondisabled group (47 \%).

\section{Relationships between indicators}

The first research question was to test the extent to which individual's self-rating of health were associated with life satisfaction and happiness perception. Table 2 presents a significant relationship between the selfrated health and the perception of happiness. For the purposes of this analysis, participants who responded they felt "not happy at all" and "don't feel very happy" the term unhappy was used to define these two responses. The analysis of the adjusted residuals reveals that within the students who report to have excellent health the percentage who felt unhappy $(10.0 \%)$ were substantially below at than the overall average (20.8\%). Further, the students who reported having a poorer health and felt very happy (16.2 \%) were substantially below than the overall average (30.9\%).

A one-way ANOVA was used to verify the differences between life-satisfaction and the three levels of self-rated health. For the purposes of this analysis, participants who responded that their health was fair or poor, the term poorer health was used to define these two responses. Results show significant differences between the three levels of self-related health $(F(2,447)=2.28, p<.001)$. The levels of life satisfaction of students with disabilities who reported to have excellent health $(M=7.6)$ or good health $(M=7.0)$, were significantly higher than students with disabilities who rated themselves as having poor health $(M=6.3)$. However, it is important to note that all three values are higher than 6 , which defines a positive level of life satisfaction.

\section{Differences between groups}

The second research question compared health selfratings between students with and without disabilities. The study found significant differences between students with and without disabilities with respect to the selfrated health measure. As shown on Table 3, the analysis

Table 1 Comparison of demographic characteristics, disable versus non disable participants

\begin{tabular}{|c|c|c|c|c|c|}
\hline & Number & $\begin{array}{l}\text { Disability } \\
\text { group }\end{array}$ & Number & $\begin{array}{l}\text { Control } \\
\text { group }\end{array}$ & Statistics \\
\hline \multicolumn{6}{|l|}{ Gender } \\
\hline Female & 120 & (56 \%) & 113 & $(47 \%)$ & \multirow{2}{*}{$\begin{array}{l}\left(x^{2}=4.21, \mathrm{df}=1\right. \\
p=.025 ; n=455)\end{array}$} \\
\hline Male & 93 & $(44 \%)$ & 129 & (53\%) & \\
\hline \multicolumn{6}{|l|}{ Grade } \\
\hline $6^{\text {th }}$ & 64 & (30 \%) & 679 & $(28 \%)$ & \multirow{3}{*}{$\begin{array}{l}\left(x^{2}=.811, \mathrm{df}=2\right. \\
p=.667 ; n=455)\end{array}$} \\
\hline $8^{\text {th }}$ & 81 & (38\%) & 102 & (42\%) & \\
\hline $10^{\text {th }}$ & 68 & (32\%) & 73 & (30 \%) & \\
\hline \multicolumn{6}{|l|}{ Nationality } \\
\hline Portuguese & 195 & (92 \%) & 227 & (95\%) & \multirow{5}{*}{$\begin{array}{l}\left(x^{2}=9.26, d f=4\right. \\
p=.055 ; n=451)\end{array}$} \\
\hline African & 11 & (5.2\%) & 3 & $(1.3 \%)$ & \\
\hline Brazilian & 0 & (0 \%) & 2 & (0.8\%) & \\
\hline $\begin{array}{c}\text { Eastern } \\
\text { countries }\end{array}$ & 0 & (0 \%) & 2 & (0.8\%) & \\
\hline Other & 5 & (2.4 \%) & 6 & $(2.5 \%)$ & \\
\hline
\end{tabular}


of adjusted residual scores revealed that students with disabilities reported significantly lower ratings to having excellent health (20.4\%), while the group without disabilities related significantly more to having excellent health $(38.6 \%)$ in comparison to the average percentage $(30.1 \%)$. The opposite was true for the poorer health status; students with disabilities reported poorer health significantly more $(30.8 \%)$ than the control group (17.4\%) in comparison to the average percentage $(23.7 \%)$.

Students with disabilities reported a much less favorable pattern of health complaints than students without disabilities, marked by significantly higher rates of psychological and physical symptoms (see Table 4). However, no differences were found between groups in the area of life satisfaction. Students with disabilities reported more psychological and physical symptoms but did not differ significantly from students without disabilities in regard to their life satisfaction.

With regard to the differences in perceptions of health by age, it was observed that the mean age of students with disabilities that related their health as excellent $(M=14)$ was significantly lower than students who related their health as poor $(M=15)[F(3,208)=3.965, p<.05]$. There was no significant difference were found in the control group between perceptions of health related to age $[F(2,238)=2.459, p>.001]$.

\section{Discussion}

Findings showed that students with disabilities who report a better self-rating of health are more satisfied with their lives. These same results were found in a study which had used the HBSC instrument with 103 institutionalized youth with physical disabilities from Portugal (Canha, 2010). Self-appraisal of health also appeared associated with the perception of happiness: youth who reported having excellent health were identified as having a sense of happiness while youth who reported having poorer health were identified as being less happy. These findings extend the literature showing the interactions between life satisfaction and health (Putnam et al. 2003) and their impact on quality of life (Edwards et al. 2003).

Significantly higher levels of health complaints, both psychological and physical, were found among students with disabilities as compared to their nondisabled peers. Moreover, students with disabilities reported a more negative self-appraisal of health than their peers without disabilities. These results corroborate other studies using the same instrument that showed adolescents with disabilities present more physical and psychological symptoms, and lower health perception than their nondisabled peers (Simões et al. 2010). In another study carried out by Denny et al. (2014), high levels of symptoms of depression were found among students with chronic health conditions reporting that their illness or disability impacted their activities, or their ability to socialize, and this was significantly higher than among students without chronic health conditions. However, contrary to our hypothesis, there were no significant differences between groups on perceived life satisfaction. This result is contrary to prior studies that found adolescents with disabilities are more dissatisfied with lives in comparison with their nondisabled peers (Watson and

Table 2 Comparison between health perception variable and happiness perception variable on disable group

\begin{tabular}{|c|c|c|c|c|c|c|}
\hline & & & \multicolumn{3}{|c|}{ Happiness perception } & \multirow[t]{2}{*}{ Total } \\
\hline & & & Very happy & Quite happy & Unhappy & \\
\hline \multirow[t]{12}{*}{ Health Perception } & \multirow[t]{4}{*}{ Excellent } & Frequency & 12 & 26 & 5 & 43 \\
\hline & & $\%$ line & $27.9 \%$ & $60.5 \%$ & $11.6 \%$ & $100.0 \%$ \\
\hline & & $\%$ column & $32.4 \%$ & $21.7 \%$ & $10.0 \%$ & $20.8 \%$ \\
\hline & & Adjusted residual & 1.9 & .4 & -2.2 & \\
\hline & \multirow[t]{4}{*}{ Good } & Frequency & 19 & 57 & 24 & 100 \\
\hline & & $\%$ line & $19.0 \%$ & $57.0 \%$ & $24.0 \%$ & $100.0 \%$ \\
\hline & & $\%$ column & $51.4 \%$ & $47.5 \%$ & $48.0 \%$ & $48.3 \%$ \\
\hline & & Adjusted residual & .4 & -.3 & -.1 & \\
\hline & \multirow[t]{4}{*}{ Poorer } & Frequency & 6 & 37 & 21 & 64 \\
\hline & & $\%$ line & $9.4 \%$ & $57.8 \%$ & $32.8 \%$ & $100.0 \%$ \\
\hline & & $\%$ column & $16.2 \%$ & $30.8 \%$ & $42.0 \%$ & $30.9 \%$ \\
\hline & & Adjusted residual & -2.1 & .0 & 1.9 & \\
\hline \multirow[t]{3}{*}{ Total } & & Frequency & 37 & 120 & 50 & 207 \\
\hline & & $\%$ line & $17.9 \%$ & $58.0 \%$ & $24.2 \%$ & 100.0 \\
\hline & & $\%$ column & $17.9 \%$ & $58.0 \%$ & $24.2 \%$ & 100.0 \\
\hline
\end{tabular}

Note. $x^{2}=9,92, d f=4, p=0.042 ; n=207$ 
Table 3 Comparison of health perception between disabled and non-disabled groups

\begin{tabular}{|c|c|c|c|c|c|}
\hline & & & \multicolumn{2}{|c|}{ Two groups } & \multirow[t]{2}{*}{ Total } \\
\hline & & & Disabled & Non-disabled & \\
\hline \multirow[t]{12}{*}{ Health Perception } & Excellent & Frequency & 43 & 93 & 136 \\
\hline & & $\%$ line & $31.6 \%$ & $68.4 \%$ & $100.0 \%$ \\
\hline & & $\%$ column & $20.4 \%$ & $38.6 \%$ & $30.1 \%$ \\
\hline & & Adjusted residual & -4.2 & 4.2 & \\
\hline & Good & Frequency & 103 & 106 & 209 \\
\hline & & $\%$ line & $49.3 \%$ & $50.7 \%$ & $100.0 \%$ \\
\hline & & $\%$ column & $48.8 \%$ & $44.0 \%$ & $46.2 \%$ \\
\hline & & Adjusted residual & 1.0 & -1.0 & \\
\hline & Poorer & Frequency & 65 & 42 & 107 \\
\hline & & $\%$ line & $60.7 \%$ & $39.3 \%$ & $100.0 \%$ \\
\hline & & $\%$ column & $30.8 \%$ & $17.4 \%$ & $23.7 \%$ \\
\hline & & Adjusted residual & 3.3 & -3.3 & \\
\hline \multirow[t]{3}{*}{ Total } & & Frequency & 211 & 241 & 452 \\
\hline & & $\%$ line & $46.6 \%$ & $53.3 \%$ & $100.0 \%$ \\
\hline & & $\%$ column & $100.0 \%$ & $100.0 \%$ & $100.0 \%$ \\
\hline
\end{tabular}

Note. $x^{2}=21.47, d f=2, p<.001 ; n=452$

Keith 2002; Sacks and Kern 2008; Edwards et al. 2003; Topolski et al. 2004). Further work is needed to explore how the perception of life-satisfaction of school-aged students with disabilities is related with their overall self-appraisal health.

Better health is related to higher life satisfaction for adolescents with disabilities. Thus, assuming that a positive self-appraisal of health may mitigate the adverse effect of illness or disability on life satisfaction (Diener, 2009), these findings suggest that health promotion is an important issue for adolescents with disabilities. Still, for adolescents with disabilities, their perception of health decreases with age in addition to being lower than their nondisabled peers. These results were also found in other studies (Lee and McCormick 2004) and support the need to reinforce the competence to promote their own health of the younger age groups as they mature through developmental stages. Based on the principle of personal empowerment, the relationship between self-reported health and other indicators suggests the need for promotion interventions that empower people with disabilities to better manage their health, already proposed by other studies (Rimmer and
Rowland 2008). Moreover, from the perspective of individuals with disabilities, health and wellness also includes being able to function autonomously-being independent and self-determined, as well as having both physical and emotional well-being (Krahn et al. 2006). This view implies that the health education should involve individuals, learning to make their own decisions, taking responsibility, and feeling empowered to adopt healthy lifestyles (Matos, 2002). It is important to note that environments must be favorable to these life styles (Edwards et al. 2003). According O'Donnell (2009), the physical and social environments in which we live are probably the most important predictors of health behaviors.

A final important point is the relationship between health and life satisfaction has been pointed out by some authors as a factor for successful transition to adulthood, including employment (Bakken and Obiakor 2008; WolfBranigin et al. 2007). In this sense, programs promoting youth involvement are critical in order to empower youth with disabilities to give them the opportunity to better manage their health and pursue future plans in a selfdetermined way.

Table 4 Differences between groups relative to scales SS-Psychological, SS- Physical Life and Life Satisfaction

\begin{tabular}{llllll}
\hline Scales & Number & Disabled & Number & Non-disabled & Statistics \\
& & M (SD) & M (SD) & \\
\hline SS-Psychological & 205 & $2.18(.967)$ & 235 & $1.76(.877)$ & $t(439)=4.708, p=.000$ \\
SS- Physical & 205 & $2.07(.869)$ & 235 & $1.68(.820)$ & $t((422)=4.806, p=.000$ \\
Life Satisfaction & 209 & $6.89(1.98)$ & 242 & $7.11(1.86)$ & $t(430)=-1.195, p=.233$ \\
\hline
\end{tabular}




\section{Conclusions}

In this study were investigated the self-ratings of health and its relationship to life satisfaction in students with disabilities. In addition, similarities and differences between students with and without disabilities regarding their self-ratings of health, life satisfaction, and psychological and physical symptoms were analyzed. It is clear from this study that there are relationships between health and satisfaction with life, and that students with disabilities present more physical and psychological symptoms, and lower health perception than their nondisabled peers. These findings reinforce the need for interventions empowering adolescents with disabilities to better manage their health. Future studies should analyze the differences regarding health-related factors and life satisfaction between different types of disabilities in a larger sample of youth in each different disability group, and control for the severity of the disability. To investigate if subjective well-being causally influences health in disable populations, longitudinal studies will be helpful. Finally, other researches should take consideration to environmental factors such as school and family factors (for example, academic achievement, positive school experiences, bullying, family structure and communication with parents).

\section{Competing interests}

The authors declare that they have no competing interests.

\section{Authors' contributions}

LC participated in the sequence alignment, drafted the manuscript, and analyzed the data. CS drafted the manuscript and analyzed the data. LO participated in the sequence alignment and reviewed the manuscript. MGM was responsible for data collection and study design. All authors read and approved the final manuscript.

\section{Author details}

'Department of Education, Social Sciences and Humanities, Faculty of Human Kinetics/University of Lisbon, (Estrada da Costa), Lisboa, (1495-688), Portugal. 'Department of Exceptional Education Department, University of Wisconsin-Milwaukee, (2400 E. Hartford Ave.), Milwaukee, (53201-0413), United States.

Received: 8 February 2016 Accepted: 7 April 2016

Published online: 20 April 2016

\section{References}

Bakken JP, Obiakor FE. Transition planning for students with disabilities: What Educators and Service Providers Can Do. Springfield: Charles C Thomas; 2008.

Brown I, Brown RI. Choice as an Aspect of Quality of Life for People With Intellectual Disabilities. Journal of Policy and Practice in Intellectual Disabilities. 2009:6(1):11-8.

Burstroem B, Fredlund P. Self-rated health: is it a good predictor of subsequent mortality among adults in lower as well as in higher social classes? Community Health. 2001;55:836-40.

Canha L. Comportamentos e Saúde nas Crianças e Jovens com Deficiência Motora. [Behaviors and Health in Children and Young People with Motor Disabilities]. Psicologia da Criança e do Adolescente. 2010;2:135-55.

Cantril H. The pattern of human concern. New Brunswick: NJ Rutgers University Press; 1965.

Currie C, Gabhainn SN, Godeau E, Roberts C, Smith R, Currie D, Barnekow, V. Inequalities in young people's health - HBSC international report from The 2005/2006 survey: Scotland Child and Adolescent Health Research Unit (CAHRU). 2008.
Currie C, Levin K, Todd J. Health Behaviour in School-aged Children: World Health Organization Collaborative Cross-National Study (HBSC): findings from the 2006 HBSC survey in Scotland, Chil Id and Adolescent Health Research Unit, The University of of Edinburgh. 2011.

Denny S, Silva M, Fleming T, Clark T, Merry S, Ameratunga S, Fortune, S. The Prevalence of Chronic Health Conditions Impacting on Daily Functioning and the Association With Emotional Well-Being Among a National Sample of High School Students. Journal of Adolescent Health. 2014;54:410. doi:10.1016/j.jadohealth.2013.09.010.

Diener E. Subjective Well-being. In: Diener E, editor. The Science of Well-Being. Dordrecht: Springer; 2009. p. 11-29.

Diener E, Chan MY. Happy People Live Longer: Subjective Well-Being Contributes to Health and Longevity. Applied psychology: health and well-being. 2011; 3(1):1-43. doi:10.1111/j.1758-0854.2010.01045.x.

Edwards TC, Patrick DL, Topolski TD. Quality of Life of Adolescents With Perceived Disabilities. Journal of Pediatric Psychology. 2003;28(4):233-41.

Hagquist C, Andrich D. Measuring subjective health among adolescents in Sweden. Social Indicators Research. 2004;68(2):201-20.

Hetland J, Torsheim T, Aarø LE. Subjective health complaints in adolescence: dimensional structure and variation across gender and age. Journal of Public Health. 2002;30(3):223-30.

Kim KM, Fox MH. Moving to a Holistic Model of Health among Persons with Mobility Disabilities. Qualitative Social Work. 2006;5(4):470-88.

Krahn GL, Putnam M, Drum CE, Powers L. Disabilities and Health: Toward a National Agenda for Research. Journal of Disability Policy Studies. 2006;17(1): 18-27. doi:10.1177/10442073060170010201.

Lee $Y$, McCormick B. Subjective well-being of people with spinal cord injury: does leisure contribute? Journal of Rehabilitation. 2004;70(3):5-12.

Matos MG. A saúde dos adolescentes portugueses: quatro anos depois. Lisboa: Faculdade de Motricidade Humana; 2002.

Matos MG. Anxiety, depression and peer relationships during adolescence: results from the Portugeuse National Health Behaviour in School-aged Children survey. European Journal of Psychology of Education. 2003; 18(1):3-14.

Matos M, Simões C, Tomé G, Gaspar T, Camacho I, Diniz J, \& Equipa do Aventura Social. A Saúde dos Adolescentes Portugueses - Hoje e em 8 anos - Relatório Preliminar do Estudo HBSC 2006. www.fmh.utl.pt/ aventurasocial.com.

O'Donnell MP. Definitions of health promotion 2.0: Embracing passion, enhancing motivation, recognizing dynamic balance, and creating opportunities. American Journal Health Promotion. 2009;24(1):iv.

Patrick DL, Edwards TC, Topolski TD. Adolescent quality of life, part II: Initial validation of a new instrument. Journal of Adolescence. 2002;25:287-300.

Putnam M, Geenen S, Powers L, Saxton M, Finney S, Dautel P. Health and wellness: people with disabilities discuss barriers and facilitators to well being. Journal of Rehabilitation. 2003;69:37-45.

Rimmer JH, Rowland JL. Health Promotion for People With Disabilities: Implications for Empowering the Person and Promoting Disability-Friendly Environments. American Journal of Lifestyle Medicine. 2008:2(5):409-20.

Sacks G, Kern L. A Comparison of Quality of Life Variables for Students with Emotional and Behavioral Disorders and Students Without Disabilities. Journal of Behavioral Education. 2008;17:111-27.

Schalock R. L. The concept of quality of life: what we know and do not know. Journal of Intellectual Disability Research. 2004;48:203-216

Simões C, Matos MG, Batista-Foguet J. Personal and social features in adolescent's health. In: Freire T, editor. Understanding Positive Life Research and Practice on Positive Psychology. Lisboa: Climepsi; 2008a. p. 107-18.

Simões C, Matos MG, Tomé G, Ferreira M. Impact of negative life events on positive health in a population of adolescents with special needs, and protective factors. Journal of Cognitive and Behavioral Psychotherapies. 2008b;8(1):53-65.

Simões C, Matos MG, Ferreira M, Tomé G. Risco e resiliência em adolescentes com necessidades educativas especiais: desenvolvimento de um programa de promoção da resiliência na adolescência. Psicologia, Saúde \& Doenças. 2010;11(1):101-19.

Topolski TD, Edwards TC, Patrick DL, Varley P, Way ME, Buesching DP. Quality of life of adolescent males with Attention-Deficit Hyperactivity Disorder. Journal of Attention Disorders. 2004;7:163-73.

Watson SMR, Keith KD. Comparing the quality of life of school-age children with and without disabilities. Mental Retardation. 2002;40:304-12. 
WHO, Regional Office for Europe. Ottawa Charter for Health Promotion. 1986. Copenhagen Retrieved from http://whqlibdoc.who.int/hq/1995/WHO_HPR_ HEP_95.1.pdf.

WHO, The world health report 1997, conquering suffering enriching humanity. Geneva. World Health Organization (WHO). 1997.

WHOQOL, Group. Development of the WHOQOL: Rationale and current status. International Journal Mental Health. 1994;23:24-56.

Wolf-Branigin M, Schuyler V, White P. Improving Quality of Life and Career Attitudes of Youth With Disabilities: Experiences From the Adolescent Employment Readiness Center. Research on Social Work Practice. 2007;17: 324-33. doi:10.1177/1049731506295623.

\section{Submit your manuscript to a SpringerOpen ${ }^{\circ}$ journal and benefit from:}

- Convenient online submission

- Rigorous peer review

- Immediate publication on acceptance

- Open access: articles freely available online

- High visibility within the field

- Retaining the copyright to your article

Submit your next manuscript at $>$ springeropen.com 